\title{
Predictors of Death Sentencing for Minority, Equal, and Majority Female Juries in Capital Murder Trials
}

\author{
Tara N. Richards \\ School of Criminal Justice, University of Baltimore, Baltimore, Maryland, USA \\ Beth E. Bjerregaard \\ Department of Criminal Justice \& Criminology, University of North Carolina-Charlotte, \\ Charlotte, North Carolina, USA \\ Joseph Cochran \\ Public Policy Program, University of North Carolina-Charlotte, Charlotte, \\ North Carolina, USA

\section{Dwayne Smith} \\ Department of Criminology and Office of the Provost, University of South Florida, Tampa, \\ Florida, USA \\ Sondra J. Fogel \\ School of Social Work and Honors College, University of South Florida, Tampa, Florida, USA
}

The relatively small body of prior research investigating whether the sex composition of juries impacts sentencing decisions has produced equivocal results. Exploring this topic further, the current study used a large sample of capital cases from North Carolina $(n=675)$ to examine (a) whether jury sex composition predicted jury capital punishment sentencing decisions; and (b) whether there were different models of sentencing for male-majority, equal male-female, and female-majority juries. When we controlled for a number of legal and extralegal factors, our findings indicated that jury sex composition was independently related to sentencing outcomes. Specifically, equal male-female juries were significantly more likely and female-majority juries were significantly less likely to choose the death penalty versus a sentence of life in prison. In addition, different models (predictors) of sentencing were revealed for each of the jury sex compositions. Implications for future research and policy are discussed.

Keywords: Death penalty, jury sex compositions, gender and criminal justice processing 
A significant body of prior research has examined the influence of various extralegal characteristics on adjudication and sentencing outcomes among homicide cases. This line of inquiry has historically focused on the impact of race on homicide sentencing decisions; however, a growing number of studies have turned their attention to the impact of sex on homicide sentencing outcomes. The results of these studies have generally found that female homicide offenders receive less severe sentences than their male counterparts (Auerhahn, 2007; Curry, Lee, \& Rodriguez, 2004; Franklin \& Fearn, 2008; Johnson, Van Wingerden, \& Nieuwbeerta, 2010). One prior study also noted that in capital trials, female homicide offenders are significantly less likely than similarly situated male offenders to receive the death penalty compared to life (Richards, Jennings, Smith, Bjerregaard, \& Fogel, 2014).

Likewise, a growing body of literature has examined the effect of victim sex on homicide processing and sanctioning decisions. Findings indicate that homicide cases with female victims result in more severe sentencing decisions (Baumer, Messner, \& Felson, 2000; Beaulieu \& Messner, 1999; Curry, 2010; Curry et al., 2004; Farrell \& Swigert, 1978; but see Auerhahn, 2007; Myers, 1979; Spohn, 1994), including greater rates of death sentences (Hindson, Potter, \& Radelet, 2006; Richards, Smith, Jennings, Bjerregaard, \& Fogel, 2014) than cases with male victims.

On a related note, there has been some interest regarding the influence of criminal justice decision makers' sex on criminal justice outcomes. Included in this body of research is a relatively small number of studies that have considered the potential impact of juror sex or jury sex diversity in sentences for homicide cases, especially in capital trials in which the death penalty is among the options presented to jurors. ${ }^{1}$ As discussed here, this modest literature has produced mixed or equivocal findings, leaving unresolved whether the sex composition of juries is related to patterns of death sentencing.

At present, serving as a juror is the only role in the capital trial that women play with any regularity, although the death qualification process can often reduce their representation on a capital jury because of the generally higher prevalence of women holding anti-death penalty attitudes compared to men (Haney, 1980; Howarth, 1994). Although existing theoretical orientations on sex/gender and criminal justice system processes provide some guidance regarding the decision-making expectations of juries with greater and lesser female representation, there remains a paucity of empirical investigations regarding the potential impact of jury sex composition on homicide trial outcomes, especially in actual cases in which the state sought the death penalty. Therefore, the purpose of this research is to empirically examine the relationship between jury sex composition and sentencing decisions in capital cases in which juries have the unique responsibility of deciding whether a defendant should receive a death sentence. In pursuit of this aim, the analyses began by assessing the direct effect of jury sex composition on capital punishment decision making (endorsing a death sentence or a sentence of life in prison). Then a series of theoretically informed hypotheses were tested and compared across models regarding the predictors of jury sentence decision making by male-majority, equal male/female, and female-majority juries.

\section{LITERATURE REVIEW}

The existing empirical literature provides inconsistent information regarding the nature of the relationship between a jury's sex composition and trial outcomes generally. Some studies have 
found that female-majority juries are more likely to find the defendant guilty (Fischer, 1997; Ford, 1986; Golding, Bradshaw, Dunlap, \& Hodell, 2007; Golding, Yozwiak, Kinstle, \& Marsil, 2005; Mills \& Bohannon, 1980; Shernock \& Russell, 2012), whereas others have demonstrated the relationship to be nonlinear, such that an increase (or decrease) in the number of female jurors does not result in a clear pattern of decision making (Craig \& Sherif, 1986; Fischer, 1997; Ford, 1986; Langworthy \& Whitehead, 1986). Furthermore, some studies have found no relationship between the sex diversity of the jury and trial outcomes (Connell, 2009; Klein \& Klastorin, 1999; LaFree, Reskin, \& Visher, 1985).

Concerning capital punishment specifically, it is noteworthy that public opinion polls over the years have consistently shown women to express less support for the death penalty than men (Bohm, 2003; Saad, 2013; Smith \& Wright, 1992), a finding replicated in some mock jury studies (e.g., Beckham, Spray, \& Pietz, 2007). So, although individuals who unequivocally oppose the death penalty are excluded from serving on capital murder juries (a judicial practice upheld by the Court in Lockhart v. McCree, 1986), prospective female jurors may indicate that they do not oppose capital punishment but in contrast to their male counterparts harbor greater ambivalence about imposing a death sentence and/or hold more exacting standards about which cases deserve that level of sanction. Indeed, as Langworthy and Whitehead (1986) found in their extensive study of individual characteristics and attitudes toward incarceration, there is a general tendency toward greater punitiveness among men.

As for studies that have specifically considered the sex of jurors as a factor in death penalty sentencing, the most relevant have used data generated by the Capital Jury Project, a research effort that engaged in extensive interviews covering a number of dimensions with individuals who had served as jurors in trials in several states in which capital punishment was sought for the convicted defendant. A finding reported from several of these studies was that of a White male (and conversely Black male) effect, especially in trials involving Black defendants and White victims (Bowers, Fluery-Steiner, \& Antonio, 2003; Bowers, Steiner, \& Sandys, 2001; Eisenberg, Garvey, \& Wells, 2001). Specifically, these studies found that the presence of White males (most especially five or more) on the jury generally increased the likelihood of a death sentence, whereas the presence of Black male jurors decreased the probability of a death sentence. This was attributed in large part to substantially less sympathetic or empathetic views of the defendant among White males. It is interesting that the racial divide was less notable among female jurors, who frequently differed more with males of their same race than among themselves. Hence, the presence of females on a jury appeared to have a considerably less pronounced effect on sentencing outcomes.

In somewhat of a departure from those findings, another Capital Jury Project study (Bowers, Brewer, \& Sandys, 2004) reaffirmed the effect of White or Black males on jury decisions but found some race-related differentials among females that led to juries with Black females being less prone to death sentencing. However, the attitudinal items explored by the researchers still displayed more pronounced racial differences among male than female jurors.

Connell (2009) also utilized Capital Jury Project data in her exploration of group dynamics among individuals serving on capital murder juries. Regarding sex, the notable finding pertinent to the present research is that the percentage of a jury composed of males did not seem to influence death sentencing when a number of control factors were taken into account (as an aside, neither did the percentage of jurors who were Black). However, Connell did uncover a higher probability of death sentences by juries in which the jurors reported having favorable perceptions 
of their jury's group climate, a finding that held even when a host of other factors were controlled for. Of note is that women were more likely than men to report their jury as having had a negative group climate. Furthermore, the perception of a more favorable group climate tended to increase in proportion to the number of men serving on those juries. Connell offered a number of speculative reasons for these differences, most of which involved gendered styles of interaction. Nevertheless, she emphasized that this did not necessarily manifest itself as a distinct sex effect in jury decision making.

\section{Theoretical Perspectives}

Although the literature is unclear about the specific nature of a relationship between jury sex composition and trial outcomes, the aforementioned literature offers support for the hypothesis that diversity in jury sex composition may interact with certain case characteristics in a gendered manner to influence outcomes. One of the more consistent findings in capital trials involves the sex of the victim. Prior research examining the effect of victim sex on capital sentence decision making has demonstrated a female victim effect whereby cases with female victims are more likely to result in death compared to cases with male victims (Holcomb, Williams, \& Demuth, 2004; Richards, Jennings, Smith, Sellers et al., 2014; Stauffer, Smith, Cochran, Fogel, \& Bjerregaard, 2006; Williams, Demuth, \& Holcomb, 2007; Williams \& Holcomb, 2004). Several theories have been advanced to explain this phenomenon that may also be relevant to the examination of jury sex diversity effects.

\section{Chivalry/Paternalism}

The chivalry/paternalism hypothesis proposes that gender role stereotypes identify women as weaker and more passive than men and thus less capable of self-sufficiency and in need of more protection than their male counterparts (Baumer et al., 2000; Curry, 2010; Curry et al., 2004; Moulds, 1980). The chivalry/paternalism hypothesis has been used to explain the more lenient treatment of female offenders by the criminal justice system (Gruhl, Spohn, \& Welch, 1981) as well as the more severe treatment of male offenders who victimize females (Baumer et al., 2000; Curry, 2010; Curry et al., 2004; Franklin \& Fearn, 2008). More specifically, such applications posit that the predominantly male criminal justice system actors are inclined to protect female offenders from the harshness of the prison system as well as to punish the victimizers of women more severely than the victimizers of men because of chivalrous and paternalistic attitudes that males should protect and defend females from danger and discomfort (Baumer et al., 2000; Curry, 2010; Curry et al., 2004). In the context of capital murder trials, this means that we would expect male-majority juries to punish defendants who killed female victims more harshly than those who killed male victims. Likewise, extant research cites chivalry/paternalism in explanations regarding the greater likelihood that capital cases including the rape-murder of women, a violation of a female victim's honor, will generate a death penalty compared to other types of felonious murders (Richards, Jennings, Smith, Sellers, et al., 2014; Shatz \& Shatz, 2011; Stauffer et al., 2006; Williams et al., 2007). Thus, we also expect that male-majority juries will be especially likely to yield death sentences for rape-murders rather than sentences of life in prison. 


\section{Focal Concerns Theory}

Previous literature examining capital sentencing has also suggested that criminal justice decision makers (e.g., prosecutors, judges, and jurors) are guided by a set of focal concerns (Richards, Jennings, Smith, Sellers, et al., 2014; Williams et al., 2007), including the defendant's blameworthiness - attributes and characteristics generally associated with criminality - as well as protection of the community and organizational considerations and constraints (Steffensmeier, Ulmer, \& Kramer, 1998). Focal concerns theory suggests that because criminal justice actors have limited case information, they often rely on stereotypes and attributions to develop a "perceptual shorthand" (Steffensmeier et al., 1998, p. 768) regarding certain types of offenders and victims. Prior literature has suggested that the focal concern regarding the defendant's blameworthiness and the related impact of a victim's perceived worthiness (Baumer et al., 2000) is quite relevant to juror sentence decision making (Richards, Jennings, Smith, Sellers, et al., 2014; Williams et al., 2007). For example, research has shown that familied victims who were married and/or had children elicited the most sympathy from jurors in capital cases (Eisenberg, Garvey, \& Wells, 2003), and their murders were more likely to result in a death sentence than cases with victims who were divorced or had never married (Phillips, 2009; but see Richards, Jennings, Smith, Sellers, et al., 2014). In comparison, victims who were engaged in illegal conduct when they were victimized are often considered less worthy of protection, and likewise their offenders are seen as less responsible or blameworthy (Gillespie, Loughran, Smith, Fogel, \& Bjerregaard, 2014; Rye, Greatrix, \& Enright, 2006; Sundby, 2003).

The victim-defendant relationship may also impact perceptions of victim worthiness, with research demonstrating that cases with victims who were strangers to the perpetrator elicit the most severe sentences (Dawson, 2004; Gross \& Mauro, 1984; Simon, 1996b; Sundby, 2003; but see Simon, 1996a). Also, race seems to play a role in perceptions of victim worthiness, with a large literature suggesting that capital cases with White victims are more likely to elicit a death sentence compared to minority victim cases (the most influential of which is Baldus, Woodworth, \& Pulaski, 1990; see also Baldus \& Woodworth, 2003, but Scheidegger, 2012, for a dissenting argument). Within this literature, there is evidence that cases with White female victims merit the most severe sentences (Holcomb et al., 2004; Williams et al., 2007; Williams \& Holcomb, 2004), though some studies have not supported this finding (Richards, Jennings, Smith, Sellers, et al., 2014; Stauffer et al., 2006).

Although the potential association between juror sex and focal concerns has yet to be explored extensively, one study by Steffensmeier and Hebert (1999) investigated how the sex of judges relates to focal concerns and may provide insight into possible relationships. Specifically, Steffensmeier and Hebert indicated that sentencing decisions by female judges are influenced more by offender characteristics (i.e., age and race) and prior record than are decisions by male judges. Such findings are attributed to the overall greater fear of crime and victimization among women compared to men and, correspondingly, the idea that female judges are more in tune with defendant culpability (technically legal aspects of the case) and blameworthiness than males. Drawing from this finding, we posit that victim characteristics (e.g., involvement in illegal activity, age, and race) will have a greater influence on male-dominated juries given that research suggests that males are significantly more likely than females to endorse victim-blaming myths and attitudes (Suarez \& Gadalla, 2010). 


\section{THE PRESENT STUDY}

As discussed earlier, the question of whether there exists a distinct sex-of-jurors effect in death sentencing decisions remains unresolved, especially when this potential effect is compared to and weighed against a host of other potentially intervening variables. Thus, the present study is unique because it utilizes a large sample of capital murder trials to investigate directly whether there are relationships between jury sex composition and capital trial sentencing recommendations, especially as manifested in juries in which females are in the minority, in the majority, or equally represented with males. Guided by the theoretical orientations discussed previously, we explore results from multivariate analyses to determine the association of the sex composition of juries - controlling for a variety of other possible influences - with patterns of death sentencing. In pursuit of this aim, the following hypotheses are explored:

\section{Chivalry/Paternalism}

Hypothesis 1: Male-majority juries will be more likely to sentence offenders who killed female victims to the death penalty than life sentences.

Hypothesis 2: Male-majority juries will be more likely to sentence offenders who perpetrated rape-murders to the death penalty than life sentences.

\section{Focal Concerns Theory}

Hypothesis 1: Compared to male-majority juries, female-majority juries' decisions to implement a death sentence will be more associated with offender characteristics (i.e., offender's age and race).

Hypothesis 2: Compared to female-majority juries, male-majority juries' decisions to implement a death sentence will be more associated with victim characteristics (i.e., victim's illegal activity, age, and race).

It should be noted here that we make no specific hypotheses concerning the sentencing patterns of juries with an equal number of males and females. Because there is no extant literature on this topic to inform a specific hypothesis, we treat the examination of this type of jury as exploratory.

\section{METHOD}

\section{Data and Sample}

The data for this research were provided by the North Carolina Capital Sentencing Project (NCCSP; see Kavanaugh-Earl, Cochran, Smith, Fogel, \& Bjerregaard, 2008, for a full description) and are composed of extensive data collected from trials in which (a) the state secured a first-degree murder conviction, (b) the death penalty was sought, and (c) the trial advanced to the sentencing phase whereby the jury was provided a form titled "Issues and Recommendation as to Punishment." The jury uses this form to record responses regarding aggravating factors submitted by the prosecution, mitigating factors submitted on behalf of the defendant, and a recommendation for a sentence of death or life (without parole since October 1994). The NCCSP 
data set contains all cases from North Carolina meeting these criteria for the period of June 1977 to December $2009(N=1,356)$. The initial date marks the return to capital punishment in North Carolina following the Furman v. Georgia (1972) decision that suspended its use and the Gregg v. Georgia (1976) decision that allowed its resumption. The latter date is the last year for which a full complement of information is available for all cases tried during that year.

Each jury recommendation in the NCCSP is treated as a unique case and so includes each decision for single offenders with multiple victims as well as multiple victims for a single offender. Furthermore, sentences in retrials are treated as unique entries, so there are instances in the data in which, because of appeals, individuals had sentencing trials in two (and in rare instances three) separate hearings for the same crime, all before different juries.

The primary source of materials used to gather data for each trial were those included in posttrial appeals, either to North Carolina's Court of Appeals or to the state's Supreme Court. When needed, supplementary information was gained from original case files. As well, newspaper accounts of the trials, when available, were reviewed.

For the purposes of this study, a subset of the data was most appropriate for the proposed analyses. This subset consisted of jury decisions made in North Carolina capital murder trials conducted after April 1991, a date marking the introduction of an "Issues and Recommendation as to Punishment" form that complied with the specifications of the U.S. Supreme Court's decision McKoy v. North Carolina (1990) regarding the submission of mitigating factors during the punishment phase of capital murder trials. Because mitigation has been shown to be an important component in predicting death sentences (Bjerregaard, Smith, Fogel, \& Palacios, 2010; Connell, 2009; Kremling, Smith, Cochran, Bjerregaard, \& Fogel, 2007), it was necessary to restrict the data to those cases in which mitigation information would be comparable (see Kremling et al., 2007, for a discussion of the ramifications of the McKoy decision for North Carolina capital sentencing). The total number of cases in the data set tried after McKoy was 935; from among these cases, juror sex information (the collection of which is discussed at length below) was available for 736 jury decisions. Among this group, the number of cases with the full contingency of information available for multivariate analysis was 675 , and this group served as the working sample for the study. The reasons for data reduction among those cases with sex-of-jury information were (a) those cases $(n=30)$ in which the jury did not find the presence of an aggravating factor and thus did not progress to a consideration of mitigation, leading to an automatic assessment of life in prison; (b) cases $(n=28)$ in which juries found themselves deadlocked and, despite instructions to the contrary, did not complete the "Issues and Recommendation as to Punishment" form, also leading to an automatic assessment of life in prison for the defendant; and (c) cases $(n=3)$ in which the marital status of the victim, a variable included in the analysis, could not be determined.

Taking into account the reasons for the data reductions, this data set represents all of the available cases in which the full capital trial proceeding was conducted (specifically, jury responses were made to both aggravation and mitigation) and an actual sentence was rendered by the jury. Nevertheless, because the 61 cases with sex-of-jury information that were excluded from the working data set all involved recommendations of life sentences, we felt it prudent to determine whether the cases had substantively different jury compositions. Comparing the working data set with one that retained the excluded cases, we found the two to have virtually identical mean numbers of female jurors (6.80 vs. 6.78) and proportional representations of categories of juries (male majority, equal, female majority) that were not different at statistically significant levels. 


\section{Measures}

\section{The Sentencing Phase of Capital Murder Trials}

Because a number of the variables made available by the NCCSP derive from the sentencing phases of trials in the data set, it is useful to briefly provide an overview of those proceedings. The sentencing phase of North Carolina capital murder trials is structured around a presentation of aggravating circumstances by the prosecution and mitigating factors by the defense. Prosecutors must prove that one or more of 11 statutory aggravating factors existed in the circumstances surrounding the crime. Following that presentation, the defense can present any of nine statutory mitigating circumstances on behalf of the defendant, as well as an unlimited number of nonstatutory mitigating factors as long as it has received prior approval from the trial judge. Jurors are asked to indicate their acceptance/rejection of each aggravator and mitigator on the "Issues and Recommendation as to Punishment" form and then are asked to qualitatively weigh the impact of aggravation versus mitigation in rendering their decision. As a note, the number of aggravating circumstances accepted by juries in the data set used here ranged from 1 to 9 (average $=2.23$ ), whereas the number of mitigators accepted varied from 0 to 50 (average $=11.96$ ).

\section{Dependent Variable}

In North Carolina, capital jurors are afforded only two sentencing options: (a) life in prison (since October 1994 without the possibility of parole); or (b) the death penalty, which must be rendered via unanimous vote. Therefore, the dependent variable, jury sentencing recommendation, was expressed dichotomously $(0=$ life in prison, $1=$ death penalty $)$. Although termed a recommendation, the jury's decision is binding unless found by the trial judge to have violated judicial procedure. In cases in which the jury becomes deadlocked and cannot agree unanimously on a recommendation, the sentence automatically reverts to life in prison.

\section{Independent Variables}

Jury sex composition was measured as the ratio of female to male jurors identified for each case (i.e., female-majority jury, equal female/male jury, and male-majority jury). Two primary means of data gathering were used to determine the total number of female jurors, given that there is no central source to which jury sex (or race) is reported. First, juror names are recorded on a trial form termed a jury box, which allowed for the analysis of gendered names when these forms were included in posttrial appeals. Although they are not a required part of the documentation in appeals cases, we were able to obtain jury box forms for 490 cases. However, there were numerous instances of jurors having gender-neutral names. When the sex of only one juror could not be determined, that single juror was not counted as female. ${ }^{2}$ If juror sex could not be assigned for more than one name in the jury box, the variable for number of female jurors was coded as missing.

Because newspaper (and other media) accounts were utilized in case reviews for the NCCSP, a second source of data was media (in large part newspaper) mention of the sex composition of the jury in trial coverage. A total of 408 cases had such information. The overlap between counts 
based on jury box analysis and newspaper accounts was 223. The bivariate correlation between these sources when matched was $.950(p<.01)$, suggesting a strong proxy value of one for the other. However, when there was divergence in the figures between the overlapping cases, the media account was used. As mentioned previously, the combination of sources yielded a final sample of 675 cases with the number of female jurors determined. Jury sex composition was coded as male-majority jury (one to five female jurors), equal male/female jury (six male and six female jurors), and female-majority jury (seven to 12 female jurors).

\section{Other Extralegal Variables}

Derived from their past utilization in death penalty sentencing research (Kavanaugh-Earl et al., 2008), a number of extralegal variables - factors that, like the sex composition of the jury, technically should not influence death penalty sentencing - were included as control variables in our analyses. These included defendant race (non-White $=0$, White $=1)$, whether the defendant was 25 years old or younger (no $=0$, yes $=1$ ), victim race (non-White $=0$, White $=1$ ), defendant sex $($ male $=0$, female $=1)$, victim sex (a control variable of particular interest in relation to Hypothesis 1 ; male $=0$, female $=1)$, whether the victim was younger than the age of $18($ no $=0$, yes $=1$ ), whether the victim was married $($ no $=0$, yes $=1)$, and whether the trial occurred in an urban jurisdiction $(\text { no }=0 \text {, yes }=1)^{3,4}$

\section{Legal Variables}

Control variables were also included that captured specific legal aspects of the case that could be expected to influence jury decisions. These included whether the jury accepted that the defendant had no significant prior criminal record as a mitigating circumstance (no $=0$, yes $=1$ ), the number of victims killed, whether victim rape prior to the murder was accepted as an aggravator (no $=0$, yes $=1$ ), the total number of aggravating factors accepted by the jury, and the total number of mitigating factors accepted by the jury.

\section{Plan of Analysis}

Initially the effects of each level of jury sex composition were examined to determine whether, at a superficial level, any apparent relationships between jury sex and death sentence recommendations existed. To explore further in a more rigorous framework, we used logistic regression analysis to estimate the odds that a jury would sentence a capital defendant to the death penalty versus life in prison, taking into account a variety of other factors that could affect a jury's sentencing recommendation. Within this framework, three separate models were estimated to test the impact of different jury sex compositions - (a) male-majority jury (five or fewer female jurors), (b) equal female/male jury (six female and six male jurors), and (c) female-majority jury (seven or more female jurors) - on death penalty decision making. Then jury sex compositionspecific models were tested to determine whether different patterns of sentencing (i.e., different significant victim characteristics and/or extralegal and legal variables) influenced sentencing decisions for juries with different sex compositions. ${ }^{5}$ 


\section{RESULTS}

A breakdown of levels of jury sex composition and associated patterns of death sentencing is shown in Table 1. As an initial impression, there certainly appeared to be no systematic exclusion of women from juries selected for capital murder trials in North Carolina. In fact, there were considerably more female-majority juries than male-majority juries (366 vs. 158 , respectively; 151 juries had equal numbers). Overall, the mean number of women on capital murder juries in this sample was 6.8 , and $54.2 \%$ of sentencing recommendations were returned by female-majority juries.

Further examination of Table 1 shows an indistinct pattern of sentencing, with two seeming anomalies: Juries with seven females were notably prone to recommend death sentences, whereas juries with eight females seemed equally disinclined to recommend a death sentence. Overall, the bivariate correlation between sex of the jury and death sentence recommendations was a weak -.035 , indicating that no direct linear relationship existed between the number of female jurors and capital sentencing decisions.

Collapsing the jury compositions into the categories that would be analyzed in further analyses, we found a more distinct, and perhaps unexpected, pattern. Although male-majority and female-majority juries made death sentence recommendations in almost equal percentages $(50 \%$ and $49 \%$, respectively), it was equal female/male juries that were most likely to assess the death penalty, with $60 \%$ of their recommendations being for a death sentence. As gleaned from the literature reviewed previously, it could have been expected that male-majority juries would have death sentencing percentages substantially higher than either equal female/male juries or, especially, female-majority juries. Clearly, no linear relationship existed between the number of female jurors and sentencing decisions in the cases in our data.

TABLE 1

Sex Composition of Juries and Death Sentence Recommendations $(n=675)$

\begin{tabular}{lcc}
\hline No. of female jurors & No. of cases & Death sentence recommendations (\%) \\
\hline 2 & 1 & 100 \\
3 & 17 & 41 \\
4 & 42 & 57 \\
5 & 98 & 48 \\
6 & 151 & 60 \\
7 & 123 & 64 \\
8 & 121 & 36 \\
9 & 78 & 51 \\
10 & 40 & 55 \\
11 & 3 & 33 \\
12 & 1 & 100 \\
Total & 675 & 53 \\
\hline
\end{tabular}

Note: Mean number of female jurors $=6.8$; bivariate correlation between number of female jurors and death sentence recommendations $=-.035(p>.05)$. 


\section{Logistic Regression Analyses}

Although a general overview of sentencing decisions and jury composition is instructive, the capital punishment literature had made it clear that jury decisions are influenced by a host of factors. Consequently, a series of logistic regression models were estimated to determine (a) whether there was a multivariate relationship between jury sex composition and capital sentence decision making and (b) whether gender diversity moderated the relationship between case characteristics and sentencing decisions. Percent change was calculated by subtracting 1 from the exponentiated coefficient $(B)$ and then multiplying this number by 100 .

First, in order to identify any potential effects of jury sex composition on the likelihood of receiving the death penalty, we estimated three models with each of the jury sex composition variables serving as the variable of interest and the remaining compositions serving as the comparison group. In essence, a model of predictors of death sentencing was replicated three times, varying only by the sex composition of the jury (male majority, equal, female majority). The results of these analyses are presented in Table 2, labeled Models 1-3.

The findings shown in Table 2 reveal that equal female/male juries (compared to all other jury sex compositions) and female-majority juries (compared to all other jury sex compositions) showed statistically significant associations with death penalty sentencing. Specifically, juries that included an equal number of female and male jurors were associated with a $65 \%$ increase in the odds of recommending the death penalty. In comparison, for juries that included seven or more female jurors the odds of deciding in favor of a death sentence were reduced by $32 \%$. With reference to the existing literature, the findings are equivocal. As expected, female-majority juries were typically less likely to recommend a death sentence when all of the factors included in the analysis were controlled for. Less predictable from the literature was the propensity for death sentencing found among female/male-equal juries, and contrary to other studies and theoretical projections, male-majority juries did not show a marked tendency toward death sentencing.

Although not the focus of this study, we note for readers that across Models 1-3, six variables demonstrated statistically significant relationships with jury sentencing decisions. Specifically, cases that included defendants who were 25 years or younger, were tried in an urban jurisdiction, had more accepted mitigators, and/or included no prior record accepted as a mitigator were significantly less likely to receive the death penalty than comparable cases without those characteristics. Conversely, cases including victim rape prior to the murder or with more aggravators accepted were significantly more likely to receive a death penalty recommendation.

Next three additional logistic regression models were estimated to investigate whether there were different models of sentencing by juries with different sex compositions. Beginning with male-majority juries (Model 4; $n=158$ ), the results presented in Table 3 demonstrated distinct differences between the main model (i.e., those variables shown to be significant in Table 2) and the male-majority model. Specifically, of the seven significant variables in the main model, only the total number of aggravators, defendant prior record, and the total number of mitigators were also significant in the male-majority model. In addition, cases with child victims were significantly more likely to receive the death penalty; note that the odds of receiving a death sentence was $232 \%$ greater for these cases than for cases with victims who were 18 years or older. Also, cases with higher numbers of aggravators were $63 \%$ more likely to receive the death penalty, whereas cases including defendants with no prior record or higher numbers of mititgators were 


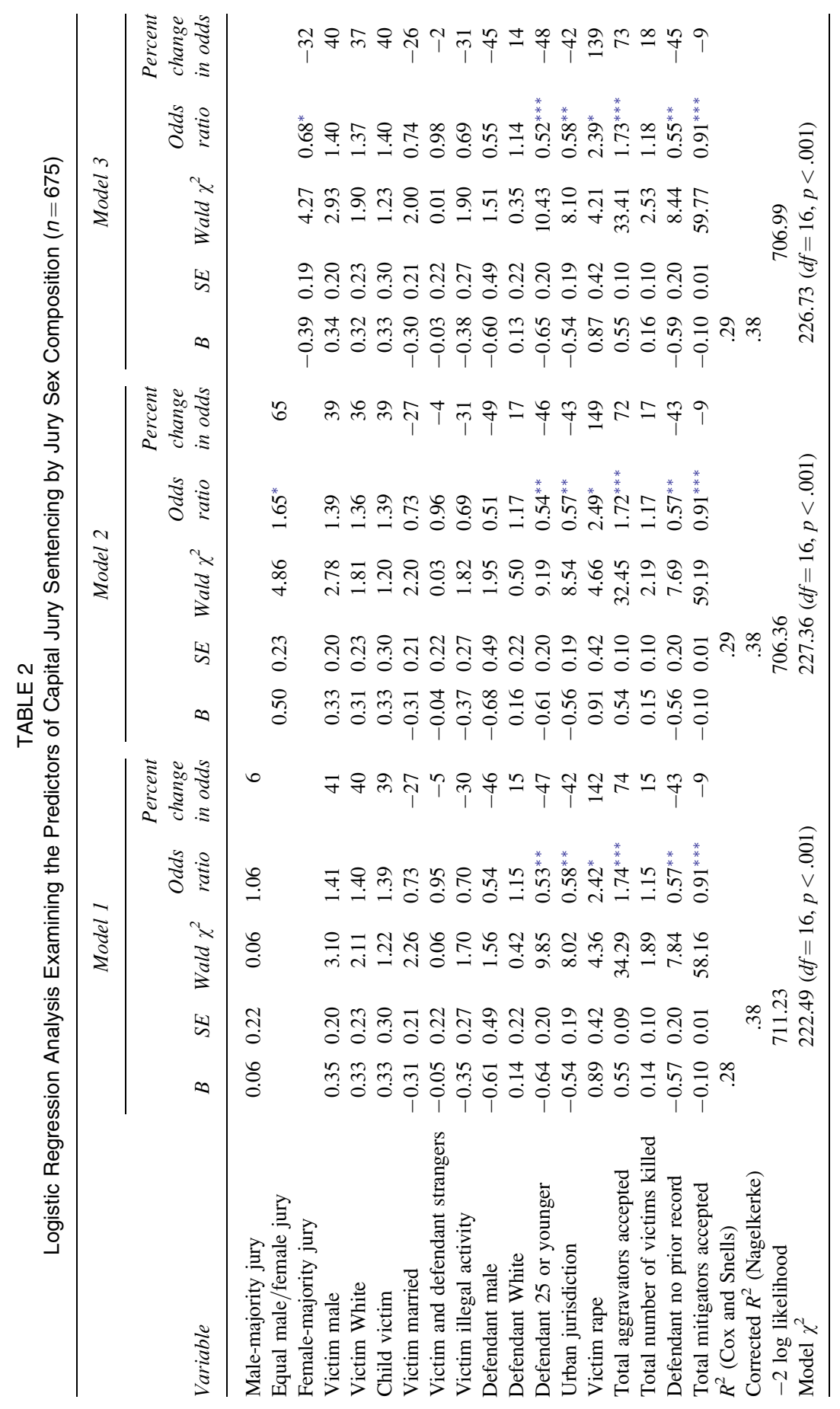




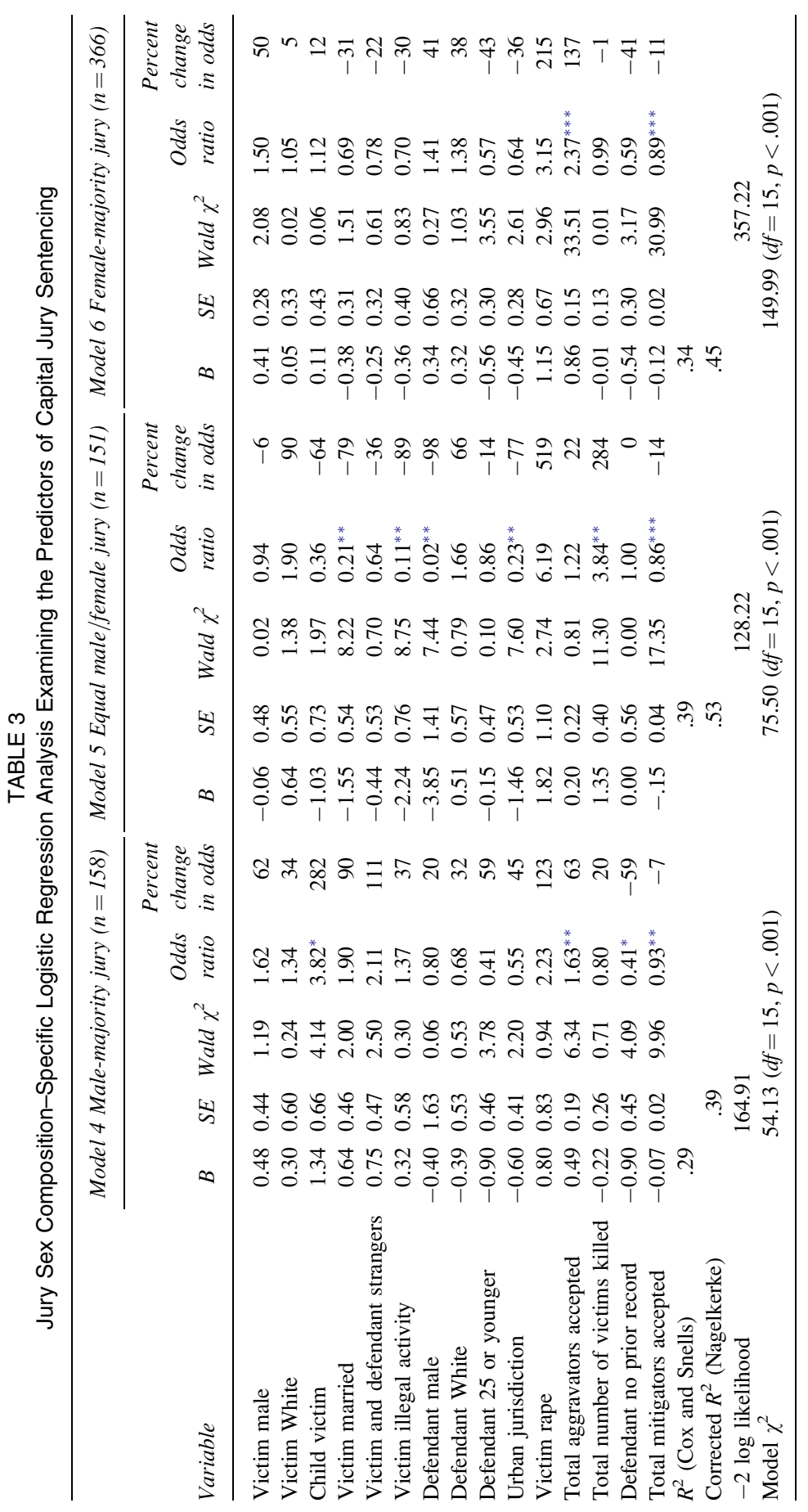


$59 \%$ and $7 \%$ less likely, respectively, to receive the death penalty versus a life sentence from male-majority juries.

In Model 5, sentencing by juries including equal numbers of female and male jurors $(n=151)$ was examined. The findings revealed that only one variable that was significant in the main model, total number of mitigators, was also significantly associated with death penalty decision making in the equal female/male model. However, this model also showed the largest number of variables statistically associated with death sentencing. These included victim illegal activity, victim marital status, defendant sex, urban/rural jurisdiction, and total number of victims. Specifically, for equal female/male juries, cases including victim illegal activity prior to the murder and cases including married victims were $79 \%$ and $89 \%$ less likely, respectively, to result in death, whereas cases with higher numbers of victims were $284 \%$ more likely to receive the death penalty. In addition, cases with male defendants, cases prosecuted in urban jurisdictions, and cases including higher numbers of accepted mitigators were associated with a $98 \%, 77 \%$, and $14 \%$ decrease, respectively, in the likelihood of receiving the death penalty from a jury with equal numbers of females/males.

Finally, Model 6 shows predictors of death sentencing among juries with a majority of female jurors $(n=366)$. The results here showed that only two predictors, total number of accepted aggravators and total number of accepted mitigators, were significantly associated with death penalty decision making; both predictors were also significant in the main model. For cases sentenced by female-majority juries, cases with higher numbers of aggravators were associated with a $137 \%$ increase in receiving the death penalty, whereas cases with higher numbers of mitigators were associated with an $11 \%$ decrease in the likelihood of receiving death. It is important to note that both of these are considered to be legal characteristics of capital murder trials that are expected to be the primary factors determining capital sentencing. The absence of statistically significant associations with extralegal characteristics in sentencing decisions among this jury grouping is a particularly intriguing finding that has not been reported in any previous literature.

\section{DISCUSSION AND CONCLUSIONS}

The limited prior research focused on the impact of jury sex composition on capital trial sentencing has suggested that jury sex diversity may have an impact on those decisions, though not necessarily in a straightforward manner. Using the lenses of the chivalry/paternalism hypothesis and focal concerns theory, the current study examined (a) whether jury sex composition predicted capital punishment decision making overall and (b) whether there were different models of sentencing for juries with fewer female than male jurors, equal numbers of female and male jurors, and a majority of female jurors.

Because our findings are both complex and varied, we summarize here the main findings and how they relate to our tested hypotheses as well as the existing literature. Initially a main model was estimated to determine whether jury sex composition was independently associated with capital sentence decision making in light of theoretically driven control variables. Two of the jury sex composition variables were significantly related to sentencing outcomes: equal female/male juries and female-majority juries. Equal female/male juries demonstrated an increased probability of deciding in favor of the death penalty compared to other jury sex compositions, whereas female-majority juries were significantly less likely to decide in favor of death 
compared to other jury sex compositions. These results are partially consistent with prior research demonstrating that females generally favor less punitive punishment than their male counterparts; however, in this vein, it is most surprising that juries that were mostly male were not associated with a greater likelihood of choosing the death penalty versus a life sentence. Although we cannot confirm it, there is a strong likelihood that the male majority was composed heavily of Whites, further running counter to some literature-based expectations.

In an effort to further understand any potential interactions between case characteristics and jury sex compositions on sentencing outcomes, we estimated logistic regression models for each category of jury. Again contradicting previous studies and our expectations given the theoretical orientations of the chivalry/paternalism hypothesis for male-majority juries, neither victim sex nor victim rape was related to sentencing decisions. However, the findings did reveal unique models of sentencing for the different jury sex compositions, demonstrating that jury sex composition did moderate the relationship between case characteristics and sentencing outcomes, with very few instances of overlap in significant variables. Results from the jury sex composition-specific models indicated that characteristics of victim worthiness were important predictors of jury decisions in favor of a death sentence for both the male-majority and equal female/male jury models. Note that the variable that was most strongly associated with decision making in cases sentenced by male-majority juries was whether the case included a child victim. Such findings provide support for focal concerns theory suggesting that innocent victims, such as children, may warrant more severe action by male-dominated juries than victims who could more easily be perceived as responsible or partially responsible for their victimization. As well, even though the concept has been constructed in gendered terms, it could be argued that the tenets of chivalry/paternalism may extend beyond women to include children. Men may also feel compelled to protect children and may be particularly outraged by the murder of a child.

In the equal female/male juries, victim marital status and victim illegal activity were important predictors of receiving a death sentence versus a life sentence. Although focal concerns theory might be suggestive of more severe sanctions for the murder of married victims than of nonmarried victims, as marriage may be indicative of familial responsibility, results here did not demonstrate this association for the other two jury models. Further in line with focal concerns theory, cases involving victim illegal activity were associated with an $89 \%$ decrease in the likelihood the case would result in a death sentence; however, this finding emerged among equal female/male juries, not male-majority juries as hypothesized.

Defendant culpability was an important predictor in each of the models; however, there were marked differences in the other significant predictors of death penalty assessments across the three different jury sex compositions. In the male-majority jury model, cases with higher numbers of aggravators, defendants with a prior record, and/or lower numbers of mitigators were more likely to receive the death penalty. In comparison, the total number of victims killed and the number of accepted mitigators, as well as an extralegal variable (defendant sex [male]), were significantly related to sentencing decisions among juries with equal numbers of female and male jurors. It is interesting, and not easily explainable, that the number of accepted aggravators and the defendant's prior record were not associated with death sentences for juries with equal numbers of female and male jurors.

For female-majority juries, only the total numbers of accepted aggravators and mitigators, both elements indicative of defendant culpability, were associated with the decision to choose the death penalty. These are the two variables that should weigh most heavily in the sentencing 
phase of capital cases, so the discovery of this pattern among female-majority juries is, from a legal perspective, exactly as it should be. Nevertheless, this finding does deviate somewhat from expectations. Specifically, given prior research indicating that because of increased fear of crime and victimization among women, sentencing decisions by female judges are influenced more by offender characteristics and prior record than are decisions by male judges (Steffensmeier \& Hebert, 1999), we expected additional defendant characteristics to be significantly related to sentencing among female-majority juries. In addition, this finding is incongruent with the voluminous capital punishment literature pertaining to juror decision making in general that reports a myriad of legal and extralegal variables as influencing sentencing outcomes.

Taken together, our findings reinforce previous results supporting the influence of focal concerns on jury sentencing decisions. However, they also suggest, rather intriguingly, that focal concerns may be gendered such that greater numbers of female jurors could contribute to a shift from a focus on defendant blameworthiness based on extralegal factors and/or victim worthiness to one that concentrates more on legal culpability. It is possible that female-majority juries are especially focused on the letter of the law when making decisions regarding the death penalty and are less influenced by extralegal variables than those juries with greater numbers of male jurors. In unpacking these results, we return to the previous literature mentioned that finds a greater reluctance to implement the death penalty among females compared to males (Bohm, 2003; Saad, 2013; Smith \& Wright, 1992). Given this ambivalence, it may be that female-majority juries are willing to choose death only in cases in which the legal factors present (i.e., several aggravators and few mitigators) in essence compel them to select that penalty. Conversely, research demonstrating the significantly greater endorsement of victim-blaming attitudes by males compared to females (Suarez \& Gadalla, 2010) may provide insight into why juries with fewer females may be more influenced by victim characteristics.

As noted earlier, the examination of juries with equal numbers of females and males was exploratory, with no specific directions for their patterns of death sentencing being made. It is of particular interest to us that this jury grouping had the most variables associated with its sentencing decisions (six), only one of which appeared in the other models. Accounting for this pattern requires speculation, but it could be that a combination of focal concerns and chivalrous attitudes intersect to make for a novel set of dynamics in jury discussions and processing. Clearly, this is a unique jury grouping that demands further study to have a better sense of how gendered factors may play a role in its decision making. Referencing Connell's (2009) work cited earlier, it could be that equal numbers of males and females on a jury contribute to positive perceptions of the group climate, with neither sex feeling outnumbered, and therefore jurors' opinions and views are not dismissed via overtly gendered dynamics.

The results discussed here serve to emphasize the importance of jury characteristics in capital trials. It would appear that the sex composition of juries is associated with sentencing outcomes, though sometimes in ways not anticipated. Similar to minorities, women have historically been systematically excluded from jury service, a practice that has since been barred by the U.S. Supreme Court (United States v. Ballard, 1944; see also the majority opinion in J.E.B. v. Alabama, 1994). The Court recognized that women bring their own experiences and viewpoints to the process of jury deliberation. There is evidence not only that women may utilize different types of moral reasoning (Gilligan, 1982) and interpret evidence differently (Golding et al., 2007; McNamara, Vattano, \& Viney, 1993) but, also important, that their 
voices or influence on the process may vary depending on their degree of representation on the jury (Fowler, 2005). Our findings support this notion. We discovered that the influence of certain case characteristics on the capital sentencing process varied depending on the sex composition of the juries. It may be that women are not contributing as robustly when they are in the minority, suggesting the importance of requirements such as jury unanimity. In fact, Ford (1986) suggested that jury diversity may increase the thoroughness and accuracy of jury deliberations and suggested that larger jury venires be used to facilitate greater diversity among those selected.

However, these are far from unequivocal conclusions. The relationship between gender and punitiveness may be complex and intersect with other identities derived from race, class, education, and political leanings (Langworthy \& Whitehead, 1986). Nevertheless, what remains perplexingly unclear from our study is why the male-dominated juries in our sample, contrary to predictions from several literatures, did not recommend death sentences in a notably disproportionate manner. However, although female-majority juries demonstrated a tendency toward assessing life sentences, the data also demonstrate that seating a female-majority jury is by no means a guarantee of escaping a death sentence recommendation.

One of the difficulties in capital sentencing is the tension between allowing for individualized sentencing determinations while not having a routinized process (e.g., mandatory sentencing) and simultaneously eliminating the influence of nonlegal factors. Although it is impossible to eliminate all potential biases, with careful attention to potential pitfalls, the influence of extralegal factors can be minimized, a goal that our results suggest seems most realized among female-majority juries.

One of the limitations of this research is that it only examined the influence of sex diversity at its most basic level - the number of female and male jurors serving. It is important to note that it did not take into account other demographic characteristics, most notably race (see Footnote 3 ), that may influence the worldviews that jurors inevitably bring to jury deliberations. We also acknowledge that our analysis was limited to a single state and that replication in a different state might yield different results. Nevertheless, the results reported here make it difficult to dismiss the idea that there is some influence of gender in the decision-making process of juries, though not in the way that we may have anticipated.

If the role of the jury is truly valued in the capital punishment process, ensuring that every eligible member of society has an equal chance to serve must be prioritized. Ensuring representation on juries can be accomplished in a variety of ways. One way is to continue to enforce existing laws that prohibit jurors from being excused from service on the basis of their gender. Given the overall composition of juries discussed here, it must be commented that this practice appears to operate well when capital juries are selected in North Carolina. As our findings have revealed, a substantial majority of capital murder trials in that state are conducted with either female-equal or female-majority juries. Furthermore, the preponderance of female-majority juries does not appear to be only a feature of the contemporary application of capital punishment in North Carolina. Overall, the full NCCSP data set has sex-of-jury information for 1,092 cases extending back to 1977 . On this basis, we found that $52.8 \%$ of cases were composed of female-majority juries, whereas female-equal juries were found in $20.6 \%$ of cases; male-majority juries returned decisions in only $26.6 \%$ of cases. Hence, women have been well represented on North Carolina capital murder juries in the post-Furman era. We note that capital sentencing decisions being disproportionately made 
by female-majority juries is a finding we have not seen discussed in any of the previous capital punishment literature.

In addition to other findings, this research lends support to the importance of jury education. As reported here, extralegal factors continue to play a role in this important process. Particularly troubling is the influence of victim characteristics on sentencing, which our research shows can vary by the sex composition of the jury. Special efforts to brief capital murder juries on the characteristics of effective group deliberation should be made, as should a more effective use of voir dire to uncover potential issues of gender bias that might serve to suppress female participation (Fowler, 2005). It has been suggested that the voir dire process can be used to educate jurors about the need for impartiality (Ford, 1986). However, others have noted the risk that this might amplify any existing biases (see Haney, 1984), so caution must be utilized in how this information would be presented. The admittedly challenging goal of the U.S. justice system is to ensure, as much as possible, that jury decisions are based on legally relevant factors. Fairness and equality in applying the ultimate punishment of a death sentence depend on an aggressive pursuit of this goal.

\section{ACKNOWLEDGMENTS}

We would like to thank Catherine Grosso and Barbara O'Brien for graciously sharing extensive data regarding the sex of jurors found in jury boxes from their study of jury selection in 173 North Carolina capital trials in which a death penalty was assessed (Grosso \& O'Brien, 2012).

\section{NOTES}

1. There are currently five states (Alabama, Delaware, Florida, Montana, Nebraska) in which judges make the final sentencing decision, with some variation among those states as to what level of jury input is required. Four other states (California, Indiana, Missouri, Ohio) have statutes that allow judges to make final decisions in exceptional circumstances (Death Penalty Information Center, 2015).

2. This strategy is acknowledged as a conservative approach that risks a Type II error in underestimating the effect of the number of female jurors on the jury decisions.

3. We note here that ideally the race of each juror would have been collected as data. However, race information was not nearly as available as sex information; it was rarely noted on jury boxes and only on occasion noted in newspaper stories. To the extent that race information appeared, it typically identified an all-White jury, leading to a grossly disproportionate representation of that type of jury among those for which race information could be located. Given the sheer number of juries/jurors involved (for this specific study, 675 trials would have entailed some 8,100 jurors), it was neither pragmatically nor financially feasible to engage in more intensive searches of public records to make race determinations for each juror.

4. The 15 North Carolina counties classified by the N.C. Rural Economic Development Center, Inc. (2013), as urban (more than 250 people per square mile in density) include Alamance, Buncombe, Cabarrus, Catawba, Cumberland, Davidson, Durham, Forsyth, Gaston, Guilford, Mecklenburg, New Hanover, Orange, Rowan, and Wake County. This definition and its rural counterpart are incorporated into North Carolina legislation.

5. Prior to these analyses, regression models were estimated using jury sex composition as the dependent variable to confirm that juries with different sex compositions were not stacked with cases with certain characteristics. The results of these models were compared with the results of the jury sex composition-specific regression models predicting sentencing outcomes. No overlaps between significant variables were observed, confirming the independent relationships between case characteristics and sentencing outcomes across jury sex compositions. 


\section{REFERENCES}

Auerhahn, K. (2007). Adjudication outcomes in intimate and non-intimate homicides. Homicide Studies, 11, 213-230.

Baldus, D. C., \& Woodworth, G. (2003). Race discrimination and the death penalty: An empirical and legal overview. In J. R. Acker, R. M. Bohm, \& C. S. Lanier (Eds.), America's experience with capital punishment (2nd ed., pp. 501-551). Durham, NC: Carolina Academic Press.

Baldus, D. C., Woodworth, G., \& Pulaski, C. A.,Jr. (1990). Equal justice and the death penalty. Boston, MA: Northeastern University Press.

Baumer, E. P., Messner, S. F., \& Felson, R. B. (2000). The role of victim characteristics in the disposition of murder cases. Justice Quarterly, 17, 281-307.

Beaulieu, M., \& Messner, S. (1999). Race, gender, and outcomes in first-degree murder cases. Journal of Poverty, 3, 47-68.

Beckham, C. M., Spray, B. J., \& Pietz, C. A. (2007). Jurors' locus of control and defendants' attractiveness in death penalty sentencing. Journal of Social Psychology, 147, 285-298.

Bjerregaard, B., Smith, M. D., Fogel, S. J., \& Palacios, W. R. (2010). Alcohol and drug mitigation in capital murder trials: Implications for sentencing decisions. Justice Quarterly, 27, 517-537.

Bohm, R. M. (2003). American death penalty opinion: Past, present, and future. In J. R. Acker, R. M. Bohm, \& C. S. Lanier (Eds.), America's experience with capital punishment (2nd ed., pp. 27-54). Durham, NC: Carolina Academic Press.

Bowers, W. J., Brewer, T. W., \& Sandys, M. (2004). Crossing racial boundaries: A closer look at the roots of racial bias in capital sentencing when the defendant is Black and victim is White. DePaul Law Review, 53, 1497-1538.

Bowers, W. J., Fluery-Steiner, B. D., \& Antonio, M. E. (2003). The capital sentencing decision: Guided discretion, reasoned moral judgment, or legal fiction. In J. R. Acker, R. M. Bohm, \& C. S. Lanier (Eds.), America's experience with capital punishment (2nd ed., pp. 413-467). Durham, NC: Carolina Academic Press.

Bowers, W. J., Steiner, B. D., \& Sandys, M. (2001). Death sentencing in Black and White: An empirical analysis of the role of jurors' race and jury racial composition. University of Pennsylvania Journal of Constitutional Law, 3, 171-275.

Connell, N. M. (2009). Death by jury: Group dynamics and capital sentencing. El Paso, TX: LFB Scholarly.

Craig, J. M., \& Sherif, C. W. (1986). The effectiveness of men and women in problem-solving groups as a function of group gender composition. Sex Roles, 14, 453-466.

Curry, T. R. (2010). The conditional effects of victim and offender ethnicity and victim gender for sentences for non-capital cases. Punishment and Society, 12, 438-462.

Curry, T. R., Lee, G., \& Rodriguez, S. F. (2004). Does victim gender increase sentence severity? Further explorations of gender dynamics and sentencing outcomes. Crime \& Delinquency, 50, 319-369.

Dawson, M. (2004). Rethinking the boundaries of intimacy at the end of the century: The role of victim-defendant relationship in criminal justice decision making over time. Law \& Society Review, 38, 105-138.

Death Penalty Information Center. (2015). Which states employ judge sentencing? Retrieved from http://www. deathpenaltyinfo.org/us-supreme-court-ring-v-arizona

Eisenberg, T., Garvey, S. P., \& Wells, M. T. (2001). Forecasting life and death: Juror race, religion, and attitude toward the death penalty. Journal of Legal Studies, 30, 277-311.

Eisenberg, T., Garvey, S. P., \& Wells, M. T. (2003). Victim characteristics and victim impact evidence in South Carolina capital cases. Cornell Law Review, 88, 306-342.

Farrell, R. A., \& Swigert, V. L. (1978). Legal disposition of inter-group and intragroup homicides. Sociological Quarterly, 19, 565-576.

Fischer, G. J. (1997). Gender effects on individual verdicts and on mock jury verdicts in a simulated acquaintance rape trial. Sex Roles, 36, 491-501.

Ford, M. C. (1986). The role of extralegal factors in jury verdicts. Justice System Journal, 11, 16-37.

Fowler, L. (2005). Gender and jury deliberations: The contributions of social science. William and Mary Journal of Women and Law, 12, 1-48.

Franklin, C.A., \& Fearn, N.E. (2008). Gender, race, and formal court decision-making outcomes: Chivalry/paternalism, conflict theory or gender conflict. Journal of Criminal Justice, 36(3), 279-290.

Furman v. Georgia, 408 U.S. 238 (1972).X 
Gillespie, L. K., Loughran, T., Smith, M. D., Fogel, S. J., \& Bjerregaard, B. (2014). Exploring the role of victim sex, victim conduct, and victim-defendant relationship in capital punishment sentencing. Homicide Studies, 18, 175-195.

Gilligan, C. (1982). In a different voice. Cambridge, MA: Harvard University Press.

Golding, J. M., Bradshaw, G. S., Dunlap, E. E., \& Hodell, E. C. (2007). The impact of mock jury gender composition on deliberations and conviction rates in a child sexual assault trial. Child Maltreatment, 12, 182-190.

Golding, J. M., Yozwiak, J. A., Kinstle, T. L., \& Marsil, D. F. (2005). The effect of gender in the perception of elder physical abuse in court. Law and Human Behavior, 29, 605-614.

Gregg v. Georgia, 428 U.S. 153 (1976).

Gross, S. R., \& Mauro, R. (1984). Patterns of death: An analysis of racial disparities in capital sentencing and homicide victimization. Stanford Law Review, 37, 27-153.

Grosso, C.M., \& O'Brien, B.O. (2012). A stubborn legacy: The overwhelming importance of race in jury selection in 173 Post-Batson North Carolina capital trials. Iowa Law Review, 97, 1531-1559.

Gruhl, J., Spohn, C., \& Welch, S. (1981). Women as policymakers: The case of trial judges. American Journal of Political Science, 25, 308-322.

Haney, C. (1980). Juries and the death penalty: Readdressing the Witherspoon question. Crime and Delinquency, 26, 512-527.

Haney, C. (1984). On the selection of capital juries: The biasing effect of the death-qualification process. Law and Human Behavior, 8(1-2), 121-132.

Hindson, S., Potter, H., \& Radelet, M. L. (2006). Race, region and death sentencing in Colorado, 1980-1999. University of Colorado Law Review, 77, 549-594.

Holcomb, J. E., Williams, M. R., \& Demuth, S. (2004). White female victims and death penalty disparity research. Justice Quarterly, 21, 877-902.

Howarth, J. W. (1994). Deciding to kill: Revealing the gender in the task handed to capital jurors. Wisconsin Law Review, 1994, 1345-1424.

J.E.B. v. Alabama, 511 U.S. 127 (1994).

Johnson, B. D., Van Wingerden, S., \& Nieuwbeerta, P. (2010). Sentencing homicide offenders in The Netherlands: Offender, victim, and situational influences in criminal punishment. Criminology, 48, 981-1017.

Kavanaugh-Earl, J., Cochran, J. K., Smith, M. D., Fogel, S. J., \& Bjerregaard, B. (2008). Racial bias and the death penalty. In M. J. Lynch, E. B. Patterson \& K. K. Childs (Eds.), Racial divide: Racial and ethnic biases in the criminal justice system (pp. 147-196). Monsey, NY: Criminal Justice Press.

Klein, K. S., \& Klastorin, T. D. (1999). Do diverse juries aid or impede justice? Wisconsin Law Review, 1999, 553-569.

Kremling, J., Smith, M. D., Cochran, J. K., Bjerregaard, B., \& Fogel, S. J. (2007). The role of mitigating factors in capital sentencing before and after McKoy v. North Carolina. Justice Quarterly, 24, 357-381.

LaFree, G. D., Reskin, B. F., \& Visher, C. A. (1985). Jurors' responses to victims' behavior and legal issues in sexual assault trials. Social Problems, 32, 389-405.

Langworthy, R. H., \& Whitehead, J. T. (1986). Liberalism and fear as explanations of punitiveness. Criminology, 24, 575-591.

Lockhart v. McCree, 476 U.S. 651 (1986).

McKoy v. North Carolina, 494 U.S. 433 (1990).

McNamara, K., Vattano, F., \& Viney, W. (1993). Verdict, sentencing, and certainty as a function of sex of juror and amount of evidence in a simulated rape trial. Psychological Reports, 72, 575-583.

Mills, C. J., \& Bohannon, W. E. (1980). Juror characteristics: To what extent are they related to jury verdicts? Judicature, $64,22-31$.

Moulds, E. F. (1980). Chivalry and paternalism: Disparities of treatment in the criminal justice system. In S. K. Datesman \& F. R. Scarpitti (Eds.), Women, crime, and justice (pp. 277-299). New York, NY: Oxford University Press.

Myers, M. A. (1979). Offended parties and official reactions: Victims and the sentencing of criminal defendants. Sociological Quarterly, 20, 529-540.

N.C. Rural Economic Development Center, Inc. (2013). Rural/urban counties in North Carolina. Retrieved from http://www.ncruralcenter.org/index.php?option=com_content $\&$ view=article \&id=75\&Itemid=126

Phillips, S. (2009). Status disparities in the capital of capital punishment. Law \& Society Review, 43, 807-837.

Richards, T.N., Jennings, W.G., Smith, M.D., Bjerregaard, B., \& Fogel, S. (2014). An examination of defendant sex disparity in capital sentencing: A propensity score matching approach. American Journal of Criminal Justice, 39, 681-697. 
Richards, T. N., Jennings, W. G., Smith, M. D., Sellers, C., Fogel, S. J., \& Bjerregaard, B. (2014). Explaining the "female victim effect" in capital punishment: An examination of victim sex specific models of juror decision-making. Crime \& Delinquency. Advance online publication. doi:10.1177/0011128714530826

, T. N., Smith, M. D., Jennings, W. G., Bjerregaard, B., \& Fogel, S. J. (2014). An examination of defendant sex disparity in capital sentencing: A propensity score matching approach. American Journal of Criminal Justice, 39, 681-697.

Rye, B. J., Greatrix, S. A., \& Enright, C. S. (2006). The case of the guilty victim: The effects of gender of victim and gender of perpetrator on attributions of blame and responsibility. Sex Roles, 54, 639-649.

Saad, L. (2013). U.S. death penalty support stable at 63\%. Retrieved from http://www.gallup.com/poll/159770/ death-penalty-support-stable.aspx?version=print

Scheidegger, K. (2012). Rebutting the myths about race and the death penalty. Ohio State Journal of Criminal Law, 10, 147-165.

Shatz, S. F., \& Shatz, N. R. (2011). Chivalry is not dead: Murder, gender, and the death penalty. Berkeley Journal of Gender, Law \& Justice, 27, 64-112.

Shernock, S., \& Russell, B. (2012). Gender and racial/ethnic difference in criminal justice decision making in intimate partner violence cases. Partner Abuse, 3, 501-530.

Simon, L. M. J. (1996a). The effect of the victim-offender relationship on the sentence length of violent offenders. Journal of Crime \& Justice, 19, 129-148.

Simon, L. M. J. (1996b). Legal treatment of the victim-offender relationship in crimes of violence. Journal of Interpersonal Violence, 11, 94-106.

Smith, M. D., \& Wright, J. D. (1992). Capital punishment and public opinion in the post-Furman era: Trends and analyses. Sociological Spectrum, 12, 127-144.

Spohn, C. A. (1994). Crime and the social control of Blacks: Offender/victim race and the sentencing of violent offenders. In G. S. Bridges \& M. A. Myers (Eds.), Inequality, crime, and social control (pp. 249-268). Boulder, CO: Westview.

Stauffer, A. R., Smith, M. D., Cochran, J. K., Fogel, S. J., \& Bjerregaard, B. (2006). The interaction between victim race and gender on sentencing outcomes in capital murder trials. Homicide Studies, 10, 98-117.

Steffensmeier, D., \& Hebert, C. (1999). Women and men policymakers: Does the judge's gender affect the sentencing of criminal defendants? Social Forces, 77, 1163-1196.

Steffensmeier, D., Ulmer, J., \& Kramer, J. (1998). The interaction of race, gender, and age in criminal sentencing: The punishment cost of young, Black, and male. Criminology, 36, 763-798.

Suarez, E., \& Gadalla, T. M. (2010). Stop blaming the victim: A meta-analysis on rape myths. Journal of Interpersonal Violence, 25, 2010-2035.

Sundby, S. E. (2003). The capital jury and empathy: The problem of worthy and unworthy victims. Cornell Law Review, $88,343-376$.

United States v. Ballard, 322 U.S. 78 (1944).

Williams, M. R., Demuth, S., \& Holcomb, J. E. (2007). Understanding the influence of victim gender in death penalty cases: The importance of victim race, sex-related victimization, and jury decision-making. Criminology, 45, 865-891.

Williams, M. R., \& Holcomb, J. E. (2004). The interactive effects of victim race and gender on death sentencing disparity findings. Homicide Studies, 8, 350-376. 